\title{
Micropropagation via multiple shoot induction in Emmenopterys henryi Oliv.
}

\author{
Mengge Zhang ${ }^{1}$, Yulong Jiang ${ }^{2}$, Huaqiang Zhao ${ }^{1}$ and Lili Song ${ }^{1}$ \\ ${ }^{1}$ School of Ecological Technology and Engineering, Shanghai Institute of Technology, Shanghai, P.R. China \\ ${ }^{2}$ State-owned Miaoshou Forest Farm, Jingde, Anhui, P.R. China
}

\begin{abstract}
Summary
Emmenopterys henryi Oliv., an endemic to China, is currently endangered. The aim of this research was to establish the procedure for rapid propagation of E. henryi via multiple shoot induction. Results showed that on media supplemented with 6-benzyladenine (BA) and 2,4-dichlorophenoxyacetic acid (2,4-D), three types of calli developed from the leaf explant, such as green, granular and compact calli liable to form shoots; white and loose calli inclined to produce hair-like roots; yellowish-white watery and translucent calli with no regeneration ability. The increase of BA to 2,4-D ratio in culture medium helped to induce shoot-forming callus. The optimal hormone combination for the callus initiation of $E$. henryi was $2 \mathrm{mg} \mathrm{L}^{-1}$ $B A$ and $0.5 \mathrm{mg} \mathrm{L}^{-1}$ 2,4-D. BA alone was more effective than combinations of BA and IBA in shoot differentiation. $2 \mathrm{mg} \mathrm{L}^{-1} \mathrm{BA}$ treatment gave the highest shoot differentiation frequency, $91 \%$, however, resulted in the most serious callus browning simultaneously. Multiple shoot induction provided effective solutions for the problem. $2 \mathrm{mg} \mathrm{L}^{-1} \mathrm{BA}$ treatment proved to be most efficient for shoot proliferation and the proliferated shoots were morphologically normal. Multiple shoot initiation by $2 \mathrm{mg} \mathrm{L}^{-1} \mathrm{BA}$ provided an effective way for rapid propagation of $E$. henryi. In addition, the effects of indole-3-butyric acid (IBA) and activated charcoal (AC) on rooting of $E$. henryi were explored. The highest rooting rate, $96.2 \%$, was obtained on medium with $1 \mathrm{mg} \mathrm{L}^{-1}$ IBA and $0.3 \mathrm{mg} \mathrm{L}^{-1} \mathrm{AC}$. About $94 \%$ of rooted plantlets survived and grew normally.
\end{abstract}

Keywords

acclimatization, browning, callus, differentiation, regeneration, rooting

\section{Introduction}

Emmenopterys henryi Oliv., the only species of the genus Emmenopterys belonging to the family Rubiaceae, is a monotypic species and endemic to China. It originated from the Cretaceous period of the Mesozoic era and is the relict plant of quaternary glaciers, which is one hundred million years old (Li and Jin, 2008). E. henryi mainly distributes in southwestern China and the Yangtze River valley. Academically, it is highly valued for morphology evolvement, phylogenetic analysis in the Rubiaceae and floristic region study of China (Peng et al., 2013; Zeng et al., 2014; Peng et al., 2017; Lu et al., 2018). As rare species, $E$. henryi was first introduced to England in 1907 by Ernest Wilson, who described E. henryi

\section{Significance of this study}

What is already known on this subject?

- Emmenopterys henryi Oliv., an endemic to China with high ornamental value, is currently endangered. Research on rapid propagation for E. henryi is in urgent need.

What are the new findings?

- This research shows that multiple shoot initiation provides effective solution for the problems resulted from callus browning in the plantlets regeneration of E. henryi.

What is the expected impact on horticulture?

- The objective of the present study was to develop an efficient protocol for multiplication and production of this species via de novo shoot organogenesis, which is important for the recovery and landscape application of the endangered species.

as one of the most strikingly beautiful trees in the Chinese forests. E. henryi was not only an excellent landscape tree for the beautiful shape and ecological function, but also a precious timber species for its fine wood (Wang, 2009; Peng et al., 2017). Its fine and flexible fibers are high-quality raw material for waxed paper and artificial cotton manufacturing. In addition, $E$. henryi is a valuable medicinal plant for its antitumor activity and therapy effect for tummy bug (Wu et al., 2013).

In recent years, the wild population of $E$. henryi has been found to decline rapidly. Besides habitat destruction and overexploitation, low nature regeneration rate plays a main role (Kang et al., 2007; Guo et al., 2017). In natural environment, E. henryi is until thirty years old when it matures and blooms every two or four years. Additionally, the seeds of $E$. henryi germinate less in natural habitat because of limitation of light and humidity (Li and Jin, 2008). So far, the species is being endangered (Qin et al., 2017). In view of this, E. henryi has been taken as the national second class protection plant of China (Fu, 1991). The aim of this study was to develop an efficient propagation system for $E$. henryi.

\section{Materials and methods}

\section{Plant material and explant preparation}

Leaves of $E$. henryi were collected during May-July from trees ( 3 years old) of natural habitats growing at ravines of State-owned Miaoshou Forest Farm, Jingde, Anhui, China (latitude $30^{\circ} 12^{\prime} \mathrm{N}$, longitude $118^{\circ} 20^{\prime} \mathrm{W}$ ). The leaves were 
rinsed in running water for $1 \mathrm{~h}$ and then surface-sterilized in $75 \%$ ethanol for 15 seconds, followed by surface sterilization in $0.2 \% \mathrm{HgCl}_{2}(\mathrm{w} / \mathrm{v})$ for $10 \mathrm{~min}$. This was followed by rinsing five times with sterile water. The sterilized leaves were cut into pieces about $2 \mathrm{~mm}^{2}$ and used for callus induction.

\section{Callus induction}

The sterilized explants were cultured on $1 / 2$ WPM medium (Phytotech) supplemented with different concentrations of 6-benzyladenine (Sigma) (BA, 0.5 or $2 \mathrm{mg} \mathrm{L}^{-1}$ ) and 2,4-dichlorophenoxyacetic acid (Sigma) (2,4-D, 0.5 or $\left.2 \mathrm{mg} \mathrm{L}^{-1}\right)$. All media contained $2 \%(\mathrm{w} / \mathrm{v})$ sucrose and $6.0 \mathrm{~g} \mathrm{~L}^{-1}$ agar. The $\mathrm{pH}$ of all media was adjusted to 5.8 before autoclaving at a pressure of $105 \mathrm{kPa}$ for $20 \mathrm{~min}$ at $121^{\circ} \mathrm{C}$. All cultured materials were incubated under $16 \mathrm{~h} / 8 \mathrm{~h}$ light/dark cycles at $24 \pm 1^{\circ} \mathrm{C}$ with relative humidity of 55-60\%. Each treatment was repeated three times. Each replicate consisted of at least 100 pieces of explants. Callus formation frequency (number of explants with callus/total number of explants cultured) was recorded after 4 weeks of culture.

\section{Multiple shoot induction}

For shoot differentiation, calli were transferred to $1 / 2$ WPM medium containing different combinations of growth regulators, including $\mathrm{BA}$ ( 1 or $2 \mathrm{mg} \mathrm{L}^{-1}$ ), kinetin (Sigma) (KT, 1 or $2 \mathrm{mg} \mathrm{L}^{-1}$ ) and indole-3-butyric acid (Sigma) (IBA, 0 or $1 \mathrm{mg} \mathrm{L}^{-1}$ ). For multiple shoot induction, the shoot tip (2-3 cm in length) were excised and cultured on $1 / 2$ WPM medium containing different concentrations of BA $\left(0,1,2\right.$ and $\left.3 \mathrm{mg} \mathrm{L}^{-1}\right)$. The culture conditions were similar to those used for callus induction. Each treatment was repeated three times and each replicate consisted of at least 100 pieces of calli or shoot tips. Shoot differentiation frequency (number of calli with shoots/total number of calli cultured) was recorded after 4 weeks of culture. Proliferation coefficient (total number of shoots/number of mother shoots) was recorded after 4 weeks of culture.

\section{Rooting and acclimatization}

For rooting, shoots were cultured on $1 / 2$ WPM medium supplemented with $0,0.5,1$, or $2 \mathrm{mg} \mathrm{L}^{-1}$ of IBA in combina-

TABLE 1. Effects of 2,4-D and BA on callus induction from leaves of $E$. henryi in vitro.

\begin{tabular}{cccl}
\hline \multicolumn{2}{c}{ Treatment } & $\begin{array}{c}\text { Callus } \\
\text { induction }\end{array}$ & Type of callus \\
\cline { 1 - 2 } $\begin{array}{c}2,4-\mathrm{D} \\
\left(\mathrm{mg} \mathrm{L}^{-1}\right)\end{array}$ & $\begin{array}{c}6-\mathrm{BA} \\
\left(\mathrm{mg} \mathrm{L}^{-1}\right)\end{array}$ & $\begin{array}{c}\text { frequency } \\
(\%)\end{array}$ & \\
\hline 2 & 0.5 & $100 \mathrm{a}$ & $\begin{array}{l}\text { Most type 2 and type 3 } \\
\text { Fewer type 1 } \\
\text { Decreasing type 2 and type 3 } \\
\text { Increasing type 1 } \\
0.5\end{array}$ \\
0.5 & $100 \mathrm{a}$ & $\begin{array}{l}\text { Most type 1 } \\
\text { Fewer type 2 and type 3 }\end{array}$ \\
\hline
\end{tabular}

2,4-D =2,4-dichlorophenoxyacetic acid; BA = 6-benzyladenine;

Type 1 = green callus with granular and compact structure; Type 2 = white callus with loose structure; Type $3=$ yellowish-white watery and translucent callus with loose and soft structure.

Each treatment was repeated three times. Each replicate consisted of at least 100 pieces of explants. Data were analyzed by one-way analysis of variance (ANOVA) using SPSS 19. Different letters mean significant difference at the 0.05 level according to Duncan's multiple range test. tion with different concentrations of activated charcoal (Sigma) (AC, $0,0.3$ or $0.5 \mathrm{mg} \mathrm{L}^{-1}$ ). The culture conditions were similar to those used for callus induction. Each treatment was repeated three times and each replicate consisted of at least 100 shoots, and rooting frequency (\%) were recorded after 4 weeks. The rooted plantlets were transplanted into the substrate (peat soil:perlite $=2: 1$ ), maintained in seedling boxes with breathable lids in greenhouse at $25 \pm 2^{\circ} \mathrm{C}$. A week later, the lids were removed and the plantlets were kept in the greenhouse for one more week. Then the plantlets might be transferred to the open field.

\section{Statistical analysis}

Each treatment was repeated three times. Each replicate consisted of at least 100 pieces of explants or calli or shoots. Data were analyzed by one-way analysis of variance (ANOVA) using SPSS 19. The means were compared using Duncan's multiple range test at the $5 \%$ level.

\section{Results and discussion}

\section{Callus induction}

As shown in Table 1, on media supplemented with varying concentrations of BA and 2,4-D, the callus induction frequency was $100 \%$, respectively. Three types of callus developed from the leaf explants. Type 1: Green callus with granular and compact structure (Figure 1b). When transferred to differentiation medium, this type of callus was inclined to form shoots. Type 2: White callus with loose structure (Figure 1a). When transferred to differentiation medium, this type of callus usually produced hair-like roots. Type 3 : Yellowish-white watery and translucent callus with loose and soft structure, which was non-regenerable on differentiation medium (Figure 1a). In medium supplemented with $0.5 \mathrm{mg} \mathrm{L}^{-1} \mathrm{BA}$ and $2 \mathrm{mg} \mathrm{L}^{-1}$ 2,4-D, higher percentage of type 2 and type 3 calli but only a small percentage of type 1 calli were induced. Comparatively, type 1 calli occurred more while type 2 and 3 calli developed less in medium supplemented with $0.5 \mathrm{mg} \mathrm{L}^{-1} \mathrm{BA}$ and $0.5 \mathrm{mg} \mathrm{L}^{-1} 2,4-\mathrm{D}$. However, in medium supplemented with $2 \mathrm{mg} \mathrm{L}^{-1} \mathrm{BA}$ and $0.5 \mathrm{mg} \mathrm{L}^{-1}$ 2,4-D, a higher percentage of type 1 callus and a lower percentage of type 2 and 3 callus were found, suggesting that the increase of BA to 2,4-D ratio in culture medium helped to induce shoot-forming callus (Table 1 ). This was in agreement with investigations of Miscanthus $\times$ ogiformis Honda 'Giganteus' (Holme and Petersen, 1996; Petersen, 1997), sorghum (Bhaskaran and Smith, 1989), mango ginger (Soundar Raju et al., 2013), and bermudagrass (Chaudhury and $\mathrm{Qu}, 2000)$. In Miscanthus $\times$ ogiformis Honda 'Giganteus', only $2.1 \%$ embryogenic and no shoot-forming callus was induced in medium without BA whereas the inclusion of BA dramatically decreased the percentage of root-forming callus and, simultaneously, increased the percentage of embryogenic and shoot-forming callus (Petersen, 1997). Similarly, in bermudagrass, addition of BA in the callus induction medium promoted the formation of regenerable callus, as reported in other grass species (Griffin and Dibble, 1995; Van der Valk et al., 1995; Chaudhury and Qu, 2000). Likewise, in sorghum, a high auxin to cytokinin ratio advanced primarily root differentiation while a high cytokinin to auxin ratio helped multiple bud development. Therefore, the optimal hormone combination for the callus initiation of E. henryi was $2 \mathrm{mg} \mathrm{L}^{-1} \mathrm{BA}$ and $0.5 \mathrm{mg} \mathrm{L}^{-1} 2,4-\mathrm{D}$. 

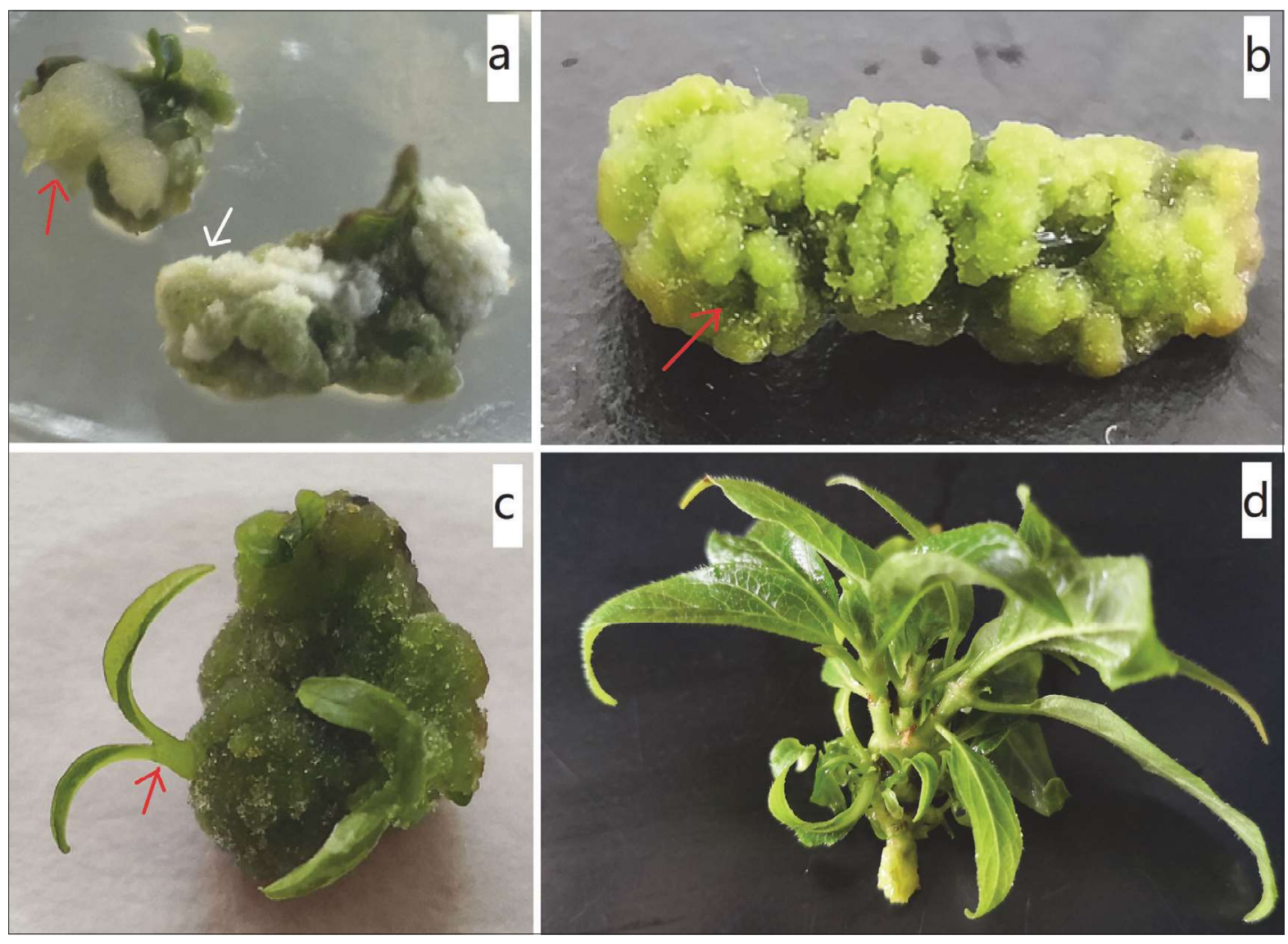

FIGURE 1. Callus development, shoot regeneration, multiple shoot induction on media with different plant growth regulators. (a) White and loose callus (type 2 callus, white arrow) and yellowish-white, watery, translucent and loose callus (type 3 callus, red arrow) formation. (b) Green, granular and compact callus formation (type 1 callus, red arrow). (c) Regeneration of shoots on type 1 callus (red arrow). (d) Multiple shoots induced on medium with $2 \mathrm{mg} \mathrm{L}^{-1} \mathrm{BA}$.

\section{Multiple shoot induction}

For shoot differentiation, type 1 calli were selected and subcultured in differentiation medium supplemented with different combinations of BA and IBA. Small shoots were observed to emerge from the appearance of green and granular calli (type 1 calli) and gradually develop into small plantlets (Figure 1c). As shown in Table 2, the highest shoot differentiation frequency obtained in medium supplemented with $2 \mathrm{mg} \mathrm{L}^{-1} \mathrm{BA}$ alone was $91 \%$ while that in medium supple- mented with $1 \mathrm{mg} \mathrm{L}^{-1} \mathrm{BA}$ alone, $63.6 \%$, was next best. But in media supplemented with BA or KT in combination with IBA, the shoot differentiation frequency were significantly lower than those obtained in media with BA alone, which agrees with previous results (Lin and Griffin, 1992; Nin et al., 1996; Panizza et al., 1997; Khanam, 2000), suggesting that BA alone was effective for shoot differentiation of $E$. henryi. In addition, the shoot differentiation frequencies on media containing only KT were remarkably lower than on those with

TABLE 2. Effects of BA, KT and IBA on shoot differentiation in E. henryi in vitro.

\begin{tabular}{|c|c|c|c|c|}
\hline \multicolumn{3}{|c|}{ Treatment } & \multirow{2}{*}{$\begin{array}{l}\text { Shoot differentiation frequency } \\
\qquad(\%)\end{array}$} & \multirow{2}{*}{$\begin{array}{l}\text { Callus browning frequency } \\
\qquad(\%)\end{array}$} \\
\hline $\begin{array}{c}\mathrm{BA} \\
\left(\mathrm{mg} \mathrm{L}^{-1}\right)\end{array}$ & KT & $\begin{array}{c}\text { IBA } \\
\left(\mathrm{mg} \mathrm{L}^{-1}\right)\end{array}$ & & \\
\hline 1 & & 0 & $63.6 \mathrm{~b}$ & $26.1 \mathrm{c}$ \\
\hline 1 & & 1 & $5.1 \mathrm{de}$ & $24.9 \mathrm{c}$ \\
\hline 2 & & 0 & $91 \mathrm{a}$ & $65.8 \mathrm{a}$ \\
\hline \multirow[t]{5}{*}{2} & & 1 & $10 \mathrm{c}$ & $50.3 b$ \\
\hline & 1 & 0 & $3.8 \mathrm{e}$ & $10.3 e$ \\
\hline & 1 & 1 & $5.6 \mathrm{de}$ & $12.5 \mathrm{de}$ \\
\hline & 2 & 0 & $7.4 d$ & $14.7 d$ \\
\hline & 2 & 1 & $7.1 \mathrm{~d}$ & $12.8 \mathrm{de}$ \\
\hline
\end{tabular}

$\mathrm{BA}=$ 6-benzyladenine; $\mathrm{KT}$ = kinetin; IBA = indole-3-butyric acid.

Each treatment was repeated three times. Each replicate consisted of at least 100 pieces of calli. Data were analyzed by one-way analysis of variance (ANOVA) using SPSS 19. Different letters mean significant difference at the 0.05 level according to Duncan's multiple range test. 
TABLE 3. Effect of BA on multiple shoots induction in E. henryi in vitro.

\begin{tabular}{lc}
\hline $\begin{array}{l}\text { Concentration } \\
\left(\mathrm{mg} \mathrm{L}^{-1}\right)\end{array}$ & Proliferation coefficient \\
\hline $\mathrm{BA}$ & $0 \mathrm{~d}$ \\
\hline 0 & $3.7 \mathrm{~b}$ \\
1 & $7.4 \mathrm{a}$ \\
2 & $2.6 \mathrm{c}$ \\
3 & \\
\hline
\end{tabular}

$\mathrm{BA}=6$-benzyladenine.

Each treatment was repeated three times. Each replicate consisted of at least 100 pieces of shoot tips. Data were analyzed by one-way analysis of variance (ANOVA) using SPSS 19. Different letters mean significant difference at the 0.05 level according to Duncan's multiple range test.

only BA (Table 2). BA has been considered to be more effective than kinetin for shoot differentiation (Tan et al., 2011; Grzegorczyk-Karolak et al., 2015; Wei et al., 2015; Zaheer and Giri, 2015), which was also consistent with our work.

What is more, while BA alone was in favor of shoot differentiation, it was found that the calli cultured on differentiation medium gradually turned brown and eventually died after the first subculture. The most serious callus browning was observed on the media supplemented with $2 \mathrm{mg} \mathrm{L}^{-1} \mathrm{BA}$ only, which was especially best for shoot differentiation (Table 2). Callus browning caused by BA treatment was also reported in bermudagrass, Piper chaba Hunt. and bamboo (Chaudhury and Qu, 2000; Rani and Dantu, 2016; Huang et al., 1989). Polyphenol oxidase (PPO), a copper-containing metalloprotein, catalyzes the oxidation of phenolics to quinones, which make brown pigments in tissues. Previous work indicated that browning callus had significantly higher PPO activity and total phenolic content than control callus (Tang and Newton, 2004; Kaewubon et al., 2015), implying that polyphenol oxidase (PPO) played a role in enzymatic callus browning (He et al., 2009; Sandhu et al., 2018). Antisense analysis on apple callus indicated that the browning potential of the transgenic apple callus, in which antisense
PPO gene was introduced and the expression of PPO was repressed, was only half the browning potential of non-transgenic callus, further proving the involvement of PPO in callus browning (Murata et al., 2001). BA had been reported to increase PPO activity (Dhruve and Vakharia, 2008; Dhruve et al., 2009), implicating that callus browning of $E$. henryi might be resulted from the promotion of BA on PPO activity. However, there is also evidence that the browning rate of callus was negatively correlated with the activity of PPO in Corydalis saxicola callus (Cen et al., 2016). What is more, in oilseed rape, it was found that application of BA had no influence on PPO activity (Wan et al., 2012). So, more research is necessary to elucidate the regulation mechanism of BA on callus browning of E. henryi.

In order to avoid the influence of callus browning on rapid propagation, the shoot tips were excised and transferred to multiple shoot induction media supplemented with varying concentrations of BA. As shown in Table 3, there was a significant difference in shoot formation between treatments lacking and containing BA. On medium with no BA, no multiple shoots formed. When BA was included in the medium, new shoots were observed to appear sequentially from both the leaf axis and the base of the stem (Figure 1d). A single shoot could multiply several times during a 4-week period. The highest shoot proliferation coefficient, 7.4, was obtained in medium supplemented with $2 \mathrm{mg} \mathrm{L}^{-1} \mathrm{BA}$ (Table 3). Higher and lower concentrations of BA yielded fewer shoots per explant. Previous works indicated that BA was effective for multiple bud formation and higher concentrations of BA were less effective (Chand and Singh, 2004; Husain et al., 2008; Zaheer and Giri, 2015; Aziz et al., 2018), which is in agreement with our results. Research on Piper chaba Hunt. showed that although shoot proliferation was optimal in the medium with BA, the shoots and medium turned brown and did not last beyond the second subculture (Rani and Dantu, 2016). What is different, in our work, the proliferated shoots were morphologically normal after four subculture (Figure 1d). Therefore, $2 \mathrm{mg} \mathrm{L}^{-1} \mathrm{BA}$ applies to shoot regeneration and multiple shoot initiation, which provides an efficient pathway for rapid propagation of E. henryi.
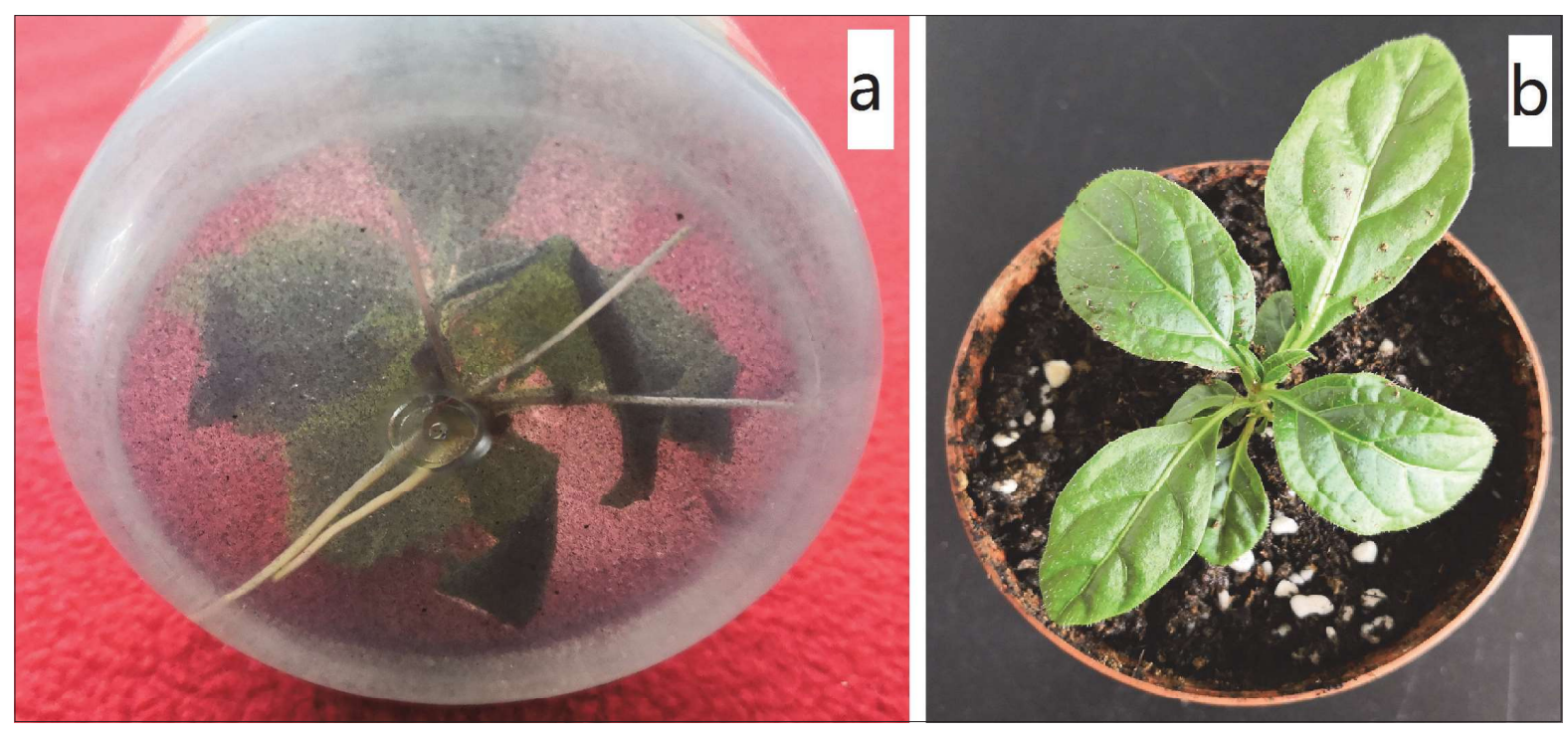

FIGURE 2. Rooting and acclimation of Emmenopterys henryi Oliv. plantlets. (a) Rooting on medium supplemented with $1 \mathrm{mg} \mathrm{L}^{-1}$ IBA in combination with $0.3 \mathrm{mg} \mathrm{L}^{-1} \mathrm{AC}$. (b) The rooted plantlets were transplanted into the substrate (peat soil:perlite = 2:1) and acclimated in greenhouse. 
TABLE 4. Effect of IBA and AC on rooting of regenerated shoots in E. henryi.

\begin{tabular}{ccc}
\hline $\begin{array}{c}\mathrm{IBA} \\
\left(\mathrm{mg} \mathrm{L}^{-1}\right)\end{array}$ & $\begin{array}{c}\mathrm{AC} \\
\left(\mathrm{mg} \mathrm{L}^{-1}\right)\end{array}$ & $\begin{array}{c}\text { Rooting frequency } \\
(\%)\end{array}$ \\
\hline 0 & 0 & $50.3 \mathrm{f}$ \\
0.5 & 0 & $60.3 \mathrm{e}$ \\
1 & 0 & $88.3 \mathrm{~b}$ \\
2 & 0 & $61.8 \mathrm{e}$ \\
0.5 & 0.3 & $78 \mathrm{c}$ \\
1 & 0.3 & $96.2 \mathrm{a}$ \\
2 & 0.3 & $72.9 \mathrm{~d}$ \\
0.5 & 0.5 & $39.3 \mathrm{~g}$ \\
1 & 0.5 & $48.6 \mathrm{f}$ \\
2 & 0.5 & $31.1 \mathrm{~h}$ \\
\hline
\end{tabular}

$\mathrm{IBA}=$ indole-3-butyric acid; $\mathrm{AC}=$ activated charcoal.

Each treatment was repeated three times. Each replicate consisted of at least 100 pieces of shoots. Data were analyzed by one-way analysis of variance (ANOVA) using SPSS 19. Different letters mean significant difference at the 0.05 level according to Duncan's multiple range test.

\section{Rooting and acclimatization}

The effects of different concentrations of IBA and activated charcoal on rooting of $E$. henryi were investigated. On medium with no plant growth regulators, the rooting frequency was $50.3 \%$. Addition of IBA promoted the rooting of $E$. henryi and the highest rooting frequency, $88.3 \%$, was obtained on medium with $1 \mathrm{mg} \mathrm{L}^{-1} \mathrm{IBA}$. Inclusion of $0.3 \mathrm{mg} \mathrm{L}^{-1} \mathrm{AC}$ further improved the rooting of $E$. henryi and made the roots thicker and stronger (Figure 2a), which agrees with the results of Lycium chinense (Kim and Park, 2017). AC might function by delaying the disintegration of the auxin in the medium, adsorbing toxic compounds like polyphenols released by cultured tissues (Thomas, 2008) or establishing polarity by darkening the medium (Sanputawong et al., 2015). However, addition of $0.5 \mathrm{mg} \mathrm{L}^{-1} \mathrm{AC}$ resulted in the decrease of rooting frequency and the roots were thinner than the control (data not shown). More seriously, the plantlets grew slowly and leaves gradually turned brown, implying that higher concentration of AC was detrimental. Similarly, in Bitter Almond, addition of activated charcoal to the rooting medium caused a sharp decrease in the rooting percentage (Kassim et al., 2012), which was also in line with previous findings that activated charcoal inhibited the rooting of peach and deciduous fruit (Antoelli and Chiariotti, 1988; Kassim et al., 2012). Actually, AC not only absorbed toxic compounds in medium but also plant growth regulators and other organic compounds, such as thiamine hydrochloride and nicotinic acid, which were essential for root growth and development (Constantin et al., 1977; Weatherhead et al., 1978). Therefore, AC might be beneficial or harmful in root induction, depending upon the medium, the tissue cultured, and the concentration of AC. In our work, $0.3 \mathrm{mg} \mathrm{L}^{-1} \mathrm{AC}$ was the best for root induction of $E$. henryi. In the subsequent acclimation experiments, about $94 \%$ of rooted plantlets survived and grew to maturity normally (Table 4, Figure $2 \mathrm{~b}$ ).

\section{Conclusion}

In conclusion, an efficient propagation protocol for E. henryi was established. The increase of BA to 2,4-D ratio proved to be beneficial to shoot-forming callus induction. $1 / 2$ WPM medium with $2 \mathrm{mg} \mathrm{L}^{-1} \mathrm{BA}$ and $0.5 \mathrm{mg} \mathrm{L}^{-1} 2,4-\mathrm{D}$ was the most effective for regenerable callus initiation. BA alone, especially, $2 \mathrm{mg} \mathrm{L}^{-1} \mathrm{BA}$, was demonstrated to be optimal not only for shoot differentiation but also multiple shoot induction, which helped to avoid the influence of callus browning problem resulted from higher BA concentration during subculture on propagation of $E$. henryi. The highest rooting rate $(96.2 \%)$ was obtained on medium with $1 \mathrm{mg} \mathrm{L}^{-1} \mathrm{NAA}$ and $0.3 \mathrm{mg} \mathrm{L}^{-1} \mathrm{AC}$. Ninety-four percent of rooted plantlets survived and grew normally in the field after acclimatization in greenhouse. The protocol established in this investigation will facilitate future mass propagation and natural resource protection of E. henryi.

\section{Acknowledgments}

This work was supported by Regional Capacity Building Program of Shanghai Municipal Science and Technology Commission: Study on rapid propagation and application technology of rare endangered plant Emmenopterys henryi Oliv. (26220I170127-17090503700); and Collaborative Innovation Platform of Fragrant Plants Resource Development (10210Q172020); and Alliance Plan of Shanghai Promotion Association of Science and Technology Achievements: The introduction and acclimation of new flower border plants in Shanghai (2017060).

\section{References}

Antonelli, M., and Chiariotti A. (1988). In vitro rooting of different peach genotypes. Acta Hortic. 227, 414-417. https://doi. org/10.17660/ActaHortic.1988.227.78.

Aziz, N.A., Tan, B.C., Othman, R.Y., and Khalid, N. (2018). Efficient micropropagation protocol and genome size estimation of an important cover crop, Mucuna bracteata DC. ex Kurz. Plant Cell Tiss. Org. Cult. 132, 267-278. https://doi.org/10.1007/s11240-0171376-3.

Bhaskaran, S., and Smith, R.H. (1989). Control of morphogenesis in Sorghum by 2,4-dichlorophenoxyacetic acid and cytokinins. Ann. Bot. 64, 217-224. https://doi.org/10.1093/oxfordjournals.aob. a087829.

Cen, Z.Y., Su, J., Deng, X.C., and Xie, Y.J. (2016). Study on total phenolic content and correlation between PPO activity and browning of Corydalis saxicola bunting callus. Crops 1, 149-153.

Chand, S., and Singh, A.K. (2004). In vitro shoot regeneration from cotyledonary node explants of a multipurpose leguminous tree Pterocarpus marsupium Roxb. In Vitro Cell. Dev. Plant 40, 464-466. https://doi.org/10.1079/IVP2004548.

Chaudhury, A., and Qu, R. (2000). Somatic embryogenesis and plant regeneration of turf-type bermudagrass: Effect of 6-benzyladenine in callus induction medium. Plant Cell Tiss. Org. Cult. 60,113-120.

Constantin, M.J., Henke, R.R., and Mansur, M.A. (1977). Effect of activated charcoal on callus growth and shoot organogenesis in tobacco. In Vitro 13, 293-296. https://doi.org/10.1007/ BF02616173.

Dhruve, J.J., and Vakharia, D.N. (2008). Groundnut response to benzyl adenine under water stress at different phenophases. Indian J. Agric. Biochem. 21, 21-26.

Dhruve, J.J., Vakharia, D.N., and Shukla, Y.M. (2009). Role of benzyladenine on oxidative enzyme system in groundnut. Indian J. Agric. Biochem. 22, 98-101.

Fu, L.G. (1991). Chinese Red Book of Plants: Rare and Endangered Plants. (Beijing: Science Press).

Griffin, J.D., and Dibble, M.S. (1995). High-frequency plant regeneration from seed-derived callus cultures of Kentucky bluegrass (Poa pratensis L.). Plant Cell Rep. 14, 721-724. https://doi. org/10.1007/BF00232655. 
Grzegorczyk-Karolak, I., Kuźma, Ł., and Wysokińska, H. (2015). The effect of cytokinins on shoot proliferation, secondary metabolite production and antioxidant potential in shoot cultures of Scutellaria alpina. Plant Cell Tiss. Org. Cult. 122, 699-708. https://doi, org/10.1007/s11240-015-0804-5.

Guo, L.J., Xue, P.P., Li, M., and Shao, X.H. (2017). Seed bank and regeneration dynamics of Emmenopterys henryi population on the western side of Wuyi Mountain, South China. J. For. Res. 28, 943-952. https://doi.org/10.1007/s11676-017-0376-9.

He, Y., Guo, X.L., Lu, R., Niu, B., Pasapula, V., Hou, P., Cai, F., Xu, Y., and Chen, F. (2009). Changes in morphology and biochemical indices in browning callus derived from Jatropha curcas hypocotyls. Plant Cell Tiss. Org. Cult. 98, 11-17. https://doi.org/10.1007/s11240-0099533-y.

Holme, I.B., and Petersen, K.K. (1996). Callus induction and plant regeneration from different explant types of Miscanthus $\times$ ogiformis Honda 'Giganteus'. Plant Cell Tiss. Org. Cult. 45, 43-52. https://doi. org/10.1007/BF00043427.

Huang, L.C., Huang, B.L., and Chen, W.L. (1989). Tissue culture investigations of bamboo - IV. Organogenesis leading to adventitious shoots and plants in excised shoot apices. Environm. Exp. Bot. 19, 307-315. https://doi.org/10.1016/0098-8472(89)90004-X.

Husain, M., Anis, M., and Shahzad, A. (2008). In vitro propagation of a multipurpose leguminous tree (Pterocarpus marsupium Roxb.) using nodal explants. Acta Physiol. Plant. 30, 353-359. https://doi. org/10.1007/s11738-007-0130-6.

Kaewubon, P., Hutadilok-Towatana, N., Silva, J.A.T.D., and Meesawat, U. (2015). Ultrastructural and biochemical alterations during browning of pigeon orchid (Dendrobium crumenatum Swartz) callus. Plant Cell Tiss. Org. Cult. 121, 53-69. https://doi.org/10.1007/ s11240-014-0678-y.

Kang, H.J., Chen, Z.L., Liu, P., Hao, C.Y., and Wei, F.M. (2007). The population structure and distribution pattern of Emmenopterys henryi in Dapanshan Natural Reserve of Zhejiang Province. Acta Ecol. Sin. 27, 389-396.

Kassim, N.E., Abou Rayya, S.M., and Ibrahim, I.A. (2012). Effect of rooting media with or without activated charcoal, auxin type and arginine concentrations on the rooting performance of bitter almond micro-cuttings. J. Appl. Sci. Res. 8(6), 3032-3037.

Khanam, N., Khoo, C., and Khan, A.G. (2000). Effects of cytokinin/ auxin combinations on organogenesis, shoot regeneration and tropane alkaloid production in Duboisia myoporoides. Plant Cell Tiss. Org. Cult. 62, 125-133.

Kim, J.K., and Park, S.U. (2017). Enhancement of in vitro rooting through growth media, gelling agents and activated charcoal in Lycium chinense. Online J. Biolog. Sci. 17, 151-156. https://doi. org/10.3844/ojbsci.2017.151.156.

Li, J.M., and Jin, Z.X. (2008). Genetic structure of endangered Emmenopterys henryi Oliv. based on ISSR polymorphism and implications for its conservation. Genetica 133, 227-234. https:// doi.org/10.1007/s10709-007-9204-z.

Lin, G.D., and Griffin, W.J. (1992). Organogenesis and a general procedure for plant regeneration from callus culture of a commercial Duboisia hybrid (D. leichhardtii $\times$ D. myoporoides). Plant Cell Rep. 11, 207-210. https://doi.org/10.1007/BF00232535.

Lu, W., Tang, Z.S., Zheng, Z.J., Ye, G.H., Chen, S.W., Wang, Y.Q., Ye, D., Liu, P., and Chen, J.H. (2018). The community composition and structural characteristics of Emmenopterys henryi Forest, an endangered species in Gutianshan, Zhejiang province. Ecology and Environm. Sci. 27, 1052-1059.
Murata, M., Nishimura, M., Murai, N., Haruta, M., Homma, S., and Itoh, Y. (2001). A transgenic apple callus showing reduced polyphenol oxidase activity and lower browning potential. Biosci. Biotechnol. Biochem. 65, 383-388. https://doi.org/10.1271/bbb.65.383.

Nin, S., Morosi, E., Schiff, S. and Bennici, A. (1996). Callus cultures of Artemisia absinthium L.: initiation, growth optimization and organogenesis. Plant Cell Tiss. Org. Cult. 45, 67-72. https://doi. org/10.1007/BF00043430.

Panizza, M., Mensualisodi, A., and Tognoni, F. (1997). Morphological differentiation in callus cultures of Lavandin - A role of ethylene. Biol. Plantarum 39, 481-489.

Peng, Y.S., Zhang, X.B., Gui, Z.M., Du, J., and Zhou, S.X. (2013). Spatial distribution pattern in Emmenopterys henryi and Phyllostachys edulis mixed forest in Lushan Mountain. Guihaia 33, 502-507.

Peng, X.L., Li, L., Zhang, G.F., Ren, X.J., Li, Q., Wu, W.X., Qiu, L., and Wang, Z.H. (2017). Species composition and diversity characteristics of Emmenopterys henryi communities in five patches in the mountainous area of southern Jiangsu. J. Plant Res. \& Environm. 26, 93-100.

Petersen, K.K. (1997). Callus induction and plant regeneration in Miscanthus $\times$ ogiformis Honda 'Giganteus' as influenced by benzyladenine. Plant Cell Tiss. Org. Cult. 49, 137-140.

Qin, H.N., Yang, Y., and Dong, S.Y. (2017). Threatened species list of China's higher plants. Biodiversity Science 25, 696-744.

Rani, D., and Dantu, P.K. (2016). Sustained shoot multiplication and method for overcoming in vitro browning in medicinally important plant, Piper chaba Hunt. Proc. Natl. Acad. Sci., India Sect. B: Bio. Sci. 86, 407-413. https://doi.org/10.1007/s40011-014-0461-1.

Sandhu, M., Wani, S.H., and Jiménez, V.M. (2018). In vitro propagation of bamboo species through axillary shoot proliferation: A review. Plant Cell Tiss. Org. Cult. 132, 27-53. https://doi.org/10.1007/ s11240-017-1325-1.

Sanputawong, S., Raknim, T., and Benchasri, S. (2015). Influence of different type of culture media and activated charcoal on callus induction and shoot multiplication of Cadaminelyrata. J. Agric. Technol. 11, 1697-1704.

Soundar Rayu, C., Kathiravan, K., Aslam, A., and Shajahan, A. (2013). An efficient regeneration system via somatic embryogenesis in mango ginger (Curcuma amada Roxb.). Plant Cell Tiss. Org. Cult. 112, 387-393. https://doi.org/10.1007/s11240-012-0244-4.

Tan, B.C., Chin C.F., and Alderson, P. (2011). Optimisation of plantlet regeneration from leaf and nodal derived callus of Vanilla planifolia Andrews. Plant Cell Tiss. Org. Cult. 105, 457-463. https://doi. org/10.1007/s11240-010-9866-6.

Tang, Wei, and Newton, R.J. (2004). Increase of polyphenol oxidase and decrease of polyamines correlate with tissue browning in Virginia pine (Pinus virginiana Mill.). Plant Sci. 167, 621-628. https://doi.org/10.1016/j.plantsci.2004.05.024.

Thomas, D.T. (2008). The role of activated charcoal in plant tissue culture. Biotechnol. Adv. 26, 618-631. https://doi.org/10.1016/j. biotechadv.2008.08.003.

Van der Valk, P., Ruis, F., Tettelaar-Schrier, A.M., and Van de Velde, C.M. (1995). Optimizing plant regeneration from seed-derived callus cultures of Kentucky bluegrass. The effect of benzyladenine. Plant Cell Tiss. Org. Cult. 40, 101-103. https://doi.org/10.1007/ BF00041125.

Wan, H.F., Lu, D., Liang, Y., Sun, F.J., and Li, J.N. (2012). Effect of cytokinins on formation of seed coat color in oilseed rape (Brassica napus). Acta Agron. Sinica 38, 1900-1907. https://doi.org/10.3724/ SP.J.1006.2012.01900. 
Wang, X.L. (2009). Application of Emmenopterys henryi to landscape design. Spec. Econ. Anim. Plant 12, 26-27.

Weatherhead, M.A., Burdon, J., and Henshaw, G.G. (1978). Some effects of activated charcoal as an additive to plant tissue culture media. Z. Pflanzenphysiol. 89, 141-147. https://doi.org/10.1016/ S0044-328X(78)80054-3.

Wei, Q., Cao, J., Qian, W., Xu, M., Li, Z., and Ding, Y. (2015). Establishment of an efficient micropropagation and callus regeneration system from the axillary buds of Bambusa ventricosa. Plant Cell Tiss. Org. Cult. 122, 1-8. https://doi.org/10.1007/s11240-015-0743-1.

Wu, X.D., He, J., Li, X.Y., Dong, L.B., Gong, X., Gao, X., Song, L.D., Li, Y., Peng, L.Y., and Zhao, Q.S. (2013). Triterpenoids and steroids with cytotoxic activity from Emmenopterys henryi. Planta Medica 79, 1356-1361. https://doi.org/10.1055/s-0033-1350645.

Zaheer, M., and Giri, C.C. (2015). Multiple shoot induction and jasmonic versus salicylic acid driven elicitation for enhanced andrographolide production in Andrographis paniculata. Plant Cell Tiss. Org. Cult. 122, 553-563. https://doi.org/10.1007/s11240-0150787-2.

Zeng, Q.C., Miao, S.Y., Tang, Z.X., Deng, D.M., Li, C.B., and Huang, F.C. (2014). Characteristics of Emmenopterys henryi population and habitat at Tianxin Nature Reserves, Lianzhou city, Guangdong province, China. Ecol. and Environm. Sci. 23, 603-609.

Received: Mar. 11, 2018

Accepted: Jan. 26, 2019

Addresses of authors:

Mengge Zhang ${ }^{1}$, Yulong Jiang ${ }^{2}$, Huaqiang Zhao ${ }^{1}$ and Lili Song ${ }^{1, *}$

${ }^{1}$ School of Ecological Technology and Engineering, Shanghai Institute of Technology, Shanghai 201418, P.R. China

${ }^{2}$ State-owned Miaoshou Forest Farm, Jingde, Anhui 242604, P.R. China

* Corresponding author; E-mail: songLL713@163.com Tel.: +86 21 60873128; Fax: +862160873128 